https://helda.helsinki.fi

The complete genome sequence of Listeria monocytogenes strain S2542 and expression of selected genes under high-pressure processing

Duru, Ilhan C

BioMed Central

2021-04-15

BMC Research Notes. 2021 Apr 15;14(1):137

http://hdl.handle.net/10138/329156

Downloaded from Helda, University of Helsinki institutional repository.

This is an electronic reprint of the original article.

This reprint may differ from the original in pagination and typographic detail.

Please cite the original version. 


\title{
The complete genome sequence of Listeria monocytogenes strain S2542 and expression of selected genes under high-pressure processing
}

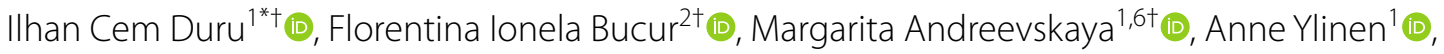 \\ Peter Crauwels ${ }^{5}$, Leontina Grigore-Gurgu² ${ }^{0}$, Bahareh Nikparvar ${ }^{3}{ }^{(0)}$, Tone Mari Rode ${ }^{4}$,

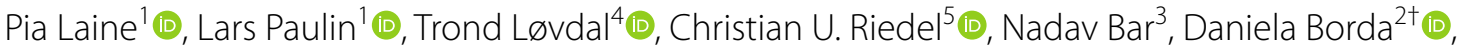 \\ Anca loana Nicolau ${ }^{2+}$ (D) and Petri Auvinen ${ }^{1+}$ (B)
}

\begin{abstract}
Objectives: The study aims to generate the whole genome sequence of L. monocytogenes strain S2542 and to compare it to the genomes of strains RO15 and ScottA. In addition, we aimed to compare gene expression profiles of $L$. monocytogenes strains S2542, ScottA and RO15 after high-pressure processing (HPP) using ddPCR.

Results: The whole genome sequence of L. monocytogenes S2542 indicates that this strain belongs to serotype 4b, in contrast to the previously reported serotype 1/2a. Strain S2542 appears to be more susceptible to the treatment at $400 \mathrm{MPa}$ compared to RO15 and ScottA strains. In contrast to RO15 and ScottA strains, viable cell counts of strain S2542 were below the limit of detection after HPP ( $400 \mathrm{MPa} / 8 \mathrm{~min}$ ) when stored at $8{ }^{\circ} \mathrm{C}$ for 24 and $48 \mathrm{~h}$. The transcriptional response of all three strains to HPP was not significantly different.
\end{abstract}

Keywords: High-pressure processing, Genome comparison, Listeria, Food safety, Gene expression, Stress recovery, Foodborne pathogen

\section{Introduction}

Listeria monocytogenes is a gram-positive foodborne bacterium that can cause severe infections in humans. Listeriosis, the associated disease, particularly affects individuals with compromised immune systems [1] and may lead to hospitalization and mortality rates of $20-30 \%$ [2]. Humans are generally infected following

\footnotetext{
*Correspondence: ilhan.duru@helsinki.f; icemduru@gmail.com ${ }^{+}$IlhanCem Duru, Florentinalonela Bucur and Margarita Andreevskaya shared first authorship

${ }^{\dagger}$ Daniela Borda, Ancaloana Nicolau and Petri Auvinen shared last authorship

${ }^{1}$ Institute of Biotechnology, University of Helsinki, Helsinki, Finland Full list of author information is available at the end of the article
}

consumption of contaminated ready-to-eat (RTE) food products that do not undergo thermal treatment during the manufacturing process or are contaminated postthermal treatment. L. monocytogenes can thrive in a range of inhospitable environmental conditions including low temperatures thus causing significant challenge to the food industry [3-6].

Recently, we have studied the transcriptional response of L. monocytogenes strains RO15 and ScottA to HPP by RNA-seq $[7,8]$. We observed that our previous gene expression results [8] are negatively correlated with the results of a previous study on HPP-induced changes in gene expression of $L$. monocytogenes strain S2542 [9]. Thus, our aim was to make a draft assembly of the

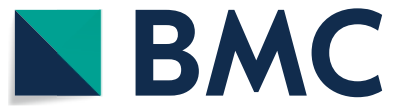

(c) The Author(s) 2021. This article is licensed under a Creative Commons Attribution 4.0 International License, which permits use, sharing, adaptation, distribution and reproduction in any medium or format, as long as you give appropriate credit to the original author(s) and the source, provide a link to the Creative Commons licence, and indicate if changes were made. The images or other third party material in this article are included in the article's Creative Commons licence, unless indicated otherwise in a credit line to the material. If material is not included in the article's Creative Commons licence and your intended use is not permitted by statutory regulation or exceeds the permitted use, you will need to obtain permission directly from the copyright holder. To view a copy of this licence, visit http://creativeco mmons.org/licenses/by/4.0/. The Creative Commons Public Domain Dedication waiver (http://creativecommons.org/publicdomain/ zero/1.0/) applies to the data made available in this article, unless otherwise stated in a credit line to the data. 
genome of the strain S2542 (obtained from Tasmanian Institute of Agricultural Research) and to compare the genome sequences of these three strains.

Based on the conflicting results regarding the HPPinduced changes in gene expression, we also performed a new set of HPP experiments under the same conditions as in our previous study [8] with all the three strains, and analyzed the transcriptional response of a number of representative genes.

\section{Methods}

\section{L. monocytogenes strain S2542 DNA isolation, library preparation, sequencing, assembly, and comparative genomics}

Genomic DNA of L. monocytogenes strain S2542 [9] was isolated as described previously [7]. A library for sequencing of the genome was generated using Nextera XT kit according to the instructions from the manufacturer (Illumina, San Diego, CA, USA). The obtained library was paired-end sequenced on a MiSeq platform using a 600 cycle sequencing kit v3 (Illumina).

Quality trimming and nextera adapter removal was done using Cutadapt v1.14 [10] with -q 25 and -m 50 options. Trimmed reads were assembled using SPades v3.13.0 [11] with default options. Prokka v1.13.3 [12] was used for functional annotation. A secondary functional annotation was done using PANNZER2 [13]. Serotype of the strain S2542 was predicted by aligning the serotype marker primers [14] to the genome using EMBOSS primersearch v 6.6.0 [15]. Multilocus sequence typing based on 7 loci (MLST), clonal complex (CC), and lineage was predicted by uploading the genome to BIGSdbLm webserver (https://bigsdb.pasteur.fr/listeria/listeria. html) [16]. Multiple genome alignment for strains RO15, ScottA and S2542 was performed using Mauve v2.4.0 [17]. Blast Average Nucleotide Identity (ANIb) analysis between strains was done using JSpeciesWS webtool [18]. Core genome alignment was done using Roary v3.12.0 [19] with the "-mafft" option for the same strains that we used previously [7]. Phylogenetic tree was created from the alignment using FastTree v2.1.11 [20].

\section{HPP experiments}

HPP experiments were conducted in order to compare the gene expression profiles of RO15, ScottA and S2542 strains. The strains were cultivated as described previously [8] and pressurized at $400 \mathrm{MPa}, 8^{\circ} \mathrm{C}$ for $8 \mathrm{~min}$. Viability of $L$. monocytogenes cells was determined after storage of the samples at $8{ }^{\circ} \mathrm{C}$ for $0 \mathrm{~min}, 24 \mathrm{~h}$ and $48 \mathrm{~h}$ by performing serial decimal dilutions of both treated samples and corresponding controls in phosphate bufferedsaline solution (PBS; Sigma Aldrich, St. Louis, SUA; $\mathrm{pH}$ 7.4) and plating dilutions on BHI (brain heart infusion) agar plate. Colony forming units were counted after incubation of the plates at $37^{\circ} \mathrm{C}$ for $48 \mathrm{~h}$.

\section{RNA extraction}

RNA was extracted from HPP-treated samples and the controls with NucleoSpin RNA kit (Macherey-Nagel, Düren, Germany) as described previously [7].

\section{ddPCR}

ddPCR was used to compare gene expression levels between strains RO15, ScottA, and S2542. Three replicate samples for each treatment and strain, and their corresponding control samples were analyzed. Expression levels of seven genes (recG, fusA, clpE, hly, agrB, ftsE, and $m s c L$ ) were quantified using strains RO15, ScottA, and S2542 samples treated with $400 \mathrm{MPa}$ and recovered for $0 \mathrm{~h}$ or $24 \mathrm{~h}$. Primers (Additional file 1: Table S1) were designed using Primer3Plus [21] and manufactured by Integrated DNA Technologies. The protocol used, including gDNA removal and RT-PCR steps, was performed as described previously [22]. To be able to compare expression levels of different samples, expression of the target genes (cDNA copies/ $\mu \mathrm{l}$ ) was normalized using concentrations of two stably expressed genes (recG and fusA). To allow comparison to our previously published RNA-Seq data, the results were expressed as $\log _{2}$ (gene concentration in treated sample/gene concentration in control sample) values.

\section{Results and discussion}

\section{Genome assembly of $L$. monocytogenes strain S2542}

We sequenced and assembled the genome of strain S2542 and compared it with the genomes of the previously studied strains; RO15 and ScottA. Assembly and annotation resulted in a $2.9 \mathrm{Mbp}$ genome consisting of 14 contigs ( $\mathrm{N} 50=477482 \mathrm{bp}$ ) with 2839 predicted coding sequence (CDS). GC-content of strain S2542 was $37.9 \%$, which is identical to the GC-content of ScottA. Based on Blast Average Nucleotide Identity (ANIb), the genome of strain S2542 was more similar to ScottA than to RO15 (ANIb scores S2542/ScottA: 99.97, S2542/RO15: 94.55). Genome alignment of strains RO15, ScottA, and S2542 indicated high similarities between the genomes. Ortholog gene prediction between three strains revealed that 31 genes were present in S2542 but absent in strains ScottA and RO15 (Additional file 1: Table S1). Most of the genes specific to strain S2542 were annotated to encode hypothetical proteins (Additional file 1: Table S1). In total, 49 genes were found in both ScottA and RO15 but not in S2542, and 47 of these were prophage genes (Additional file 1: Table S1). Thus, the differences in genome sequence most likely do not explain the differences in gene expression response to HPP described in 
our previous study on RO15 and ScottA and study presented for strain S2542 [8, 9].

Based on PHASTER prophage prediction, two small regions in S2542 (Contig1:183471-206364: $22.8 \mathrm{~kb}$; Contig2: 99648-114057: 14.4 kb) were annotated as a prophage with a low confidence score. Homolog of these regions were seen in both strain RO15 and ScottA. We did not observe CRISPR-Cas or anti-CRISPR genes within the strain S2542 genome.

Based on genome sequence analysis using BIGSdb [16], multilocus sequence typing (based on seven loci) assigned strain S2542 to ST-145. In addition, based on genome sequence, the clonal complex $(\mathrm{CC})$ of strain S2542 was CC2 and it belongs to the Lineage I, as ScottA. Serotype prediction based on the genome suggested that strain S2542 belongs to PCR-serogroup 4b. By contrast S2542 was reported to belong to serogroup $1 / 2$ a based on an antigen test [9]. Pan-genome analysis showed that strain S2542 harboured similar genes as serotype 4b strains (Fig. 1a). Core genome alignment tree visualization also supported assignment of S2542 to serotype 4b, since two clear clusters were observed for serotype $4 \mathrm{~b}$ strains (F2365, ScottA, S2542) and serotype 1/2a strains (2HF33, RO4, RO15, MB5, C7, EGD-e, AB199, AB120) (Fig. 1a.)

\section{Viable cell count after HPP}

To assess cell recovery capacity after HPP, all three strains were treated at $400 \mathrm{MPa}$ and $8{ }^{\circ} \mathrm{C}$ for $8 \mathrm{~min}$ and colony forming units (CFU) were enumerated immediately after treatment and after storage for 24 and $48 \mathrm{~h}$ at $8{ }^{\circ} \mathrm{C}$ (Fig. 1b). For all three strains $\mathrm{CFU} / \mathrm{ml}$ were higher for the samples plated immediately after HPP $(t=0 \mathrm{~min})$ compared to the samples stored for 24 and $48 \mathrm{~h}$. Also, the reduction in $\mathrm{CFU} / \mathrm{ml}$ at $\mathrm{t}=0 \mathrm{~min}$ after $\mathrm{HPP}$ compared to untreated controls was significantly higher for S2542 than for ScottA and RO15. Moreover, after $24 \mathrm{~h}$ and 48 of storage no viable cells could be detected for S2542, i.e. CFU/ml for all replicates of the high pressure treated samples were below the limit of detection, whereas for ScottA and RO15 CFU were detected at least for some of the replicates at these timepoints. We previously predicted that certain phage genes, CRISPR-Cas system and anti-CRISPR genes might play a role in highpressure resistance based on pan-genome analysis [7]. Strain S2542 does not harbour CRISPR-Cas system, nor anti-CRISPR genes. This might be one of the reasons for higher susceptibility to HPP in strain S2542.

\section{HPP-induced changes in expression of representative genes}

In order to investigate the contradictory results of HPP-induced gene expression between the Bowman

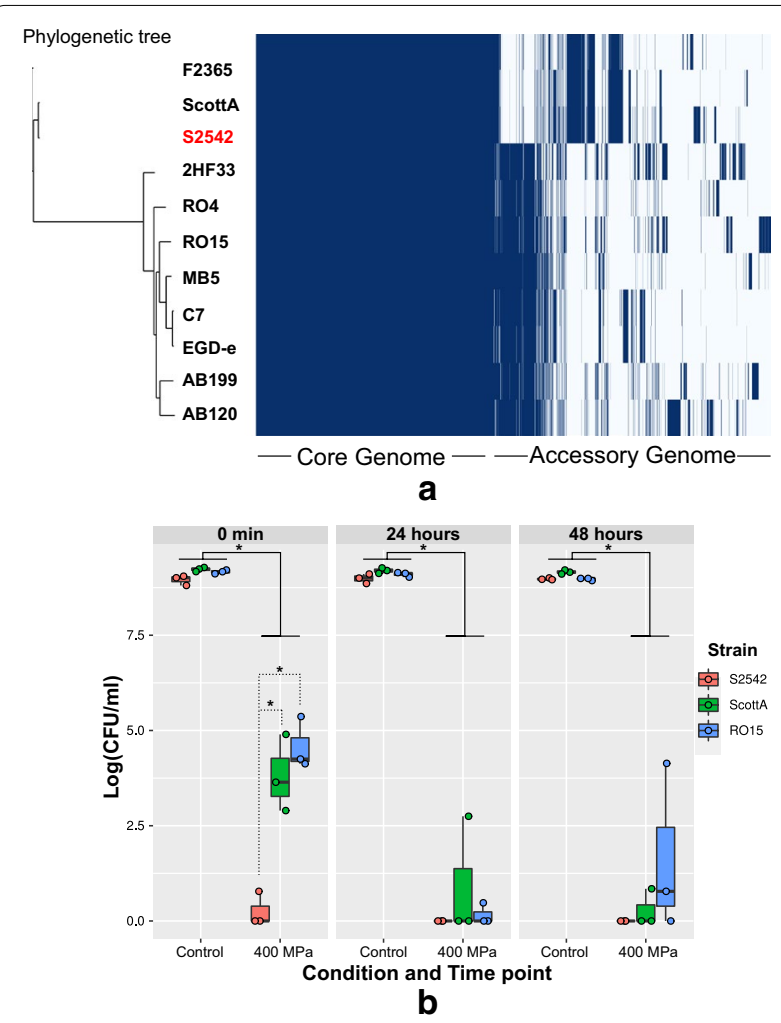

Fig. 1 a Pan-genome visualization of selected strains, $\mathbf{b}$ viability ( $\log (\mathrm{CFU} / \mathrm{ml})$ ) of L. monocytogenes strain S2542, ScottA, and $\mathrm{RO} 15$ before and after the pressure treatment $400 \mathrm{MPa}, 8 \mathrm{~min}$. a Phylogenetic tree have been calculated using the core genomes of the indicated strains. L. monocytogenes strain names were shown at the end of the phylogenetic tree branch. The matrix shows presence (blue) and absence (white) of the core and strain-specific genes. $\mathbf{b}$ Effect of HPP on cell survival. 0 min represents samples plated on agar just after pressure treatment, $24 \mathrm{~h}$ and $48 \mathrm{~h}$ represent samples that were allowed to recover for $24 \mathrm{~h}$ and $48 \mathrm{~h}$ at $8{ }^{\circ} \mathrm{C}$ and plated on agar. Strain S2542 is presented in red, ScottA in green, and $\mathrm{RO} 15$ in blue. For each experimental group individual values of three biological replicates (HPP of independent bacterial cultures) and box-and-whiskers with median and 25th-75th percentile are shown. Data was analysed by pairwise Student's t-test and differences between groups were considered statistically significant at $p$-values $<0.05$ (indicated by *)

et al. [9] study and our previous results [8], a number of genes that showed strong negative correlation between the two studies were selected and their expression levels were analysed by ddPCR approach. In contrast, we did not observe any difference in the HPP-induced expression changes of the selected genes between these strains. Furthermore, gene expression changes at $400 \mathrm{MPa}$ after $24 \mathrm{~h}$ for strains ScottA and S2542 were significantly correlated (Pearson correlation; $r=0.97$ ) (Table 1). This indicates that the gene expression responses of strains S2542 and ScottA are 
Table 1 Comparison of two studies [8, 9] and ddPCR-based expression changes for strain RO15, ScottA and S2542

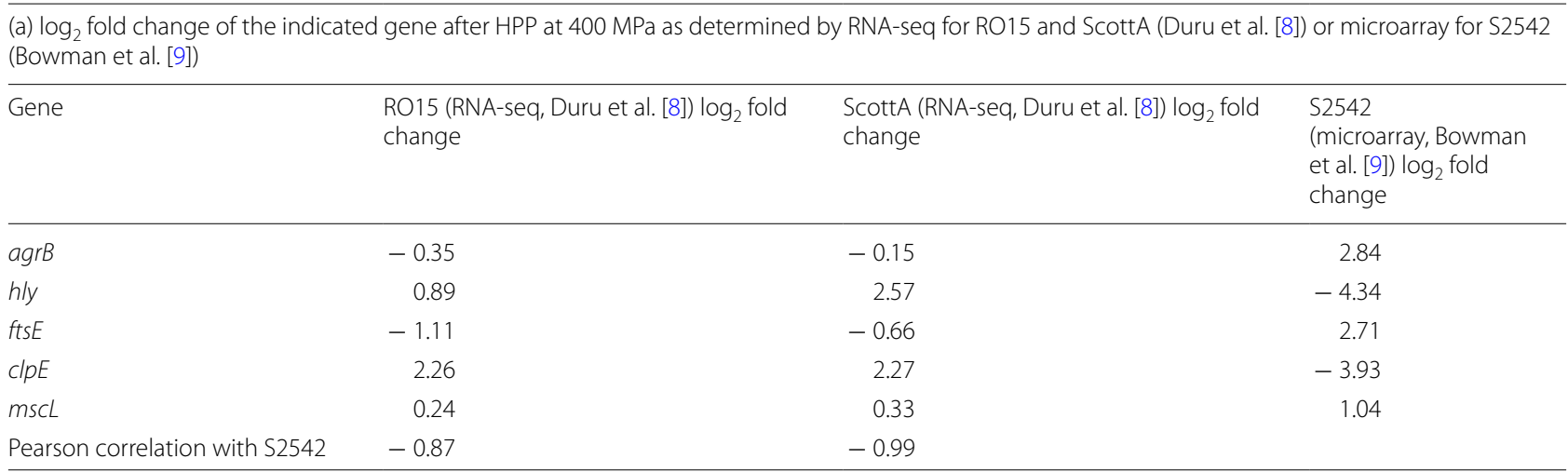

(b) $\log _{2}$ fold change of the indicated gene immediately after HPP at $400 \mathrm{MPa}$ as determined by ddPCR for all three strains (this study)

\begin{tabular}{lrrr}
\hline Gene & RO15 & ScottA & S2542 \\
\hline agrB & -0.10 & -0.16 & -0.32 \\
hly & -0.02 & 0.34 & 0.36 \\
ftsE & -0.30 & -0.06 & 0.20 \\
ClpE & 0.27 & 0.27 & 0.57 \\
msCL & 0.01 & -0.73 & 0.83 \\
Pearson correlation with S2542 & 0.49 & -0.24 & \\
\hline
\end{tabular}

(c) $\log _{2}$ fold change of the indicated gene immediately after HPP at $400 \mathrm{MPa}$ and storage for $24 \mathrm{~h}$ as determined by ddPCR for all three strains (this study)

\begin{tabular}{lrll}
\hline Gene & RO15 & ScottA & S2542 \\
\hline agrB & 0.36 & 0.09 & 0.59 \\
hly & -0.06 & 0.08 & 0.45 \\
ftsE & 0.02 & 0.60 & 1.78 \\
ClpE & 0.28 & 0.21 & 0.35 \\
msCL & 0.57 & 0.82 & 2.30 \\
Pearson correlation with S2542 & 0.38 & 0.97 & \\
\hline
\end{tabular}

a $\log _{2}$ fold change results of the two different studies $[8,9]$ with samples treated at $400 \mathrm{MPa}$ and correlation of the RNAseq results to the DNA microarray results. $\mathbf{b}$ ddPCR $\log _{2}$ fold change results at 0 min after $400 \mathrm{MPa}$ treatment comparison with data from strains RO15, ScottA and S2542 showing the correlation of the gene expression between them. $\mathbf{c d d P C R} \log _{2}$ fold change results at $24 \mathrm{~h}$ after $400 \mathrm{MPa}$ treatment with data from strains RO15, ScottA, and S2542 showing the correlation of the gene expression between them

similar in these experimental conditions. No significant differences were observed between RO15 and S2542 (Table 1). Thus, expression profiles of the selected genes in response to HPP appear to be not significantly different between the strains. The contradictory results between our previous RNA-seq study [8] and the microarray and $\mathrm{qPCR}$ data reported by Bowman et al. [9] are difficult to explain, but could be potentially explained by the different experimental conditions $\left(8{ }^{\circ} \mathrm{C}-8\right.$ min HPP exposure in Duru et al. [8] and $15{ }^{\circ} \mathrm{C}-5$ min HPP exposure in Bowman et al. [9]) or difference of the growth of the bacteria during the experiments.

The correlation of our previous RNA-seq results [8, Accession number: PRJEB34771] and current ddPCR results were also investigated. $\log _{2}$ fold changes of selected genes were correlated (Pearson correlation; $\mathrm{r}=0.95$ and 0.64 for strain RO15 and ScottA, respectively) for both strains at $0 \mathrm{~min}$ timepoint. However, at the 24 h timepoint, no clear correlation was observed for the selected genes. This indicates gene expression levels immediately after HPP (0 min timepoint) were consistent between two different experiments $[8$ and this study], but after a long incubation period $(24 \mathrm{~h}$ timepoint) gene expression levels differed.

\section{Conclusion}

In conclusion, we provide the whole draft genome sequence of Listeria monocytogenes strain S2542. The genome sequence revealed that strain S2542 belongs to 
serotype $4 \mathrm{~b}$, although it has previously been reported to belong to serotype 1/2a. Analysis of viable cell count at different timepoints after HPP suggests that S2542 is more sensitive to HPP than ScottA or RO15. Previous results of two studies on HPP-induced gene expression in S2542 on the one hand and RO15 and ScottA on the other hand were in disagreement $[8,9]$. Here, we conducted transcriptional analysis comparing the HPPinduced changes of all three strains directly. The results suggest that despite differences in sensitivity and recovery from HPP, none of the strains respond significantly differently to HPP, at least under the conditions tested and for the genes analyzed.

\section{Limitations}

In the present study, the transcriptional response of five different genes were compared between three different strains of L. monocytogenes. Although genes were carefully selected and representative for two previous studies, it is possible that the global gene expression response of S2542 may still be different than that of RO15 and/or ScottA.

\author{
Abbreviations \\ HPP: High pressure processing; ddPCR: Digital droplet PCR; MLST: Multilocus \\ sequence typing; CC: Clonal complex.
}

\section{Supplementary Information}

The online version contains supplementary material available at https://doi. org/10.1186/s13104-021-05555-2.

Additional file 1: Table S1. The list of orthologous genes within strains and primers that were used in $\mathrm{ddPCR}$ experiments.

\section{Acknowledgements}

L. monocytogenes S2542 was kindly provided by John P. Bowman. We want to thank Kirsi Lipponen, Eeva-Marja Turkki and Paula Collin for performing the NGS procedures for this project. We wish to acknowledge CSC-IT Center for Science, Finland, for computational resources.

\section{Authors' contributions}

PA, AIN, DB, TL, CUR, and NB conceived and designed the study. TMR, LG, TL, $F I B, L G G, B N, A I N$, and DB collected the samples and performed the pressure treatments and viable cell count. ICD, MA, and PL performed the bioinformatics analyses. AY performed RNA extraction and ddPCR. LP organized NGS assays. PC extracted DNA. ICD and PA drafted the manuscript. All authors have read and approved the final manuscript.

\section{Funding}

This study was supported within the ERA-IB2 consortium "SafeFood" (ID: ERAIB-16-247014) by grants from Academy of Finland to PA (307856 and 311717), by a grant of the Executive Agency for Higher Education, Research, Development and Innovation Funding in Romania to AIN (International and European Cooperation - 250 Subprogramme 3.2 - Horizon 2020 - Contract No. 15/2017) and by a grant of the German Ministry for Education and Research to CUR (Grant No: 031B0268). ICD supported by the MBDP doctoral program. The funders had no role in study design, data collection and interpretation, or the decision to submit the work for publication.

\section{Availability of data and materials}

All sequencing data and assembled genome have been deposited in the European Nucleotide Archive (ENA) under Accession code PRJEB42816. For pan-genome analysis, we publicly available genome assemblies of $L$. monocytogenes strain ScottA (https://www.ncbi.nlm.nih.gov/assembly/GCF_ 000212455.1), strain RO15 (https://www.ncbi.nlm.nih.gov/assembly/GCF_ 902827145.1), strain EGDe (https://www.ncbi.nlm.nih.gov/assembly/GCF 000196035.1), strain 2HF33 (https://www.ncbi.nlm.nih.gov/assembly/GCA 902838845.1), strain C7 (https://www.ncbi.nlm.nih.gov/assembly/GCA_90283 7585.1), strain MB5 (https://www.ncbi.nlm.nih.gov/assembly/GCA_90283 8455.1), strain RO4 (https://www.ncbi.nlm.nih.gov/assembly/GCA_90283 3935.1), strain AB120 (https://www.ncbi.nlm.nih.gov/assembly/GCA_90283 7535.1), strain AB199 (https://www.ncbi.nlm.nih.gov/assembly/GCA_90283 7525.1), and strain F2365 (https://www.ncbi.nlm.nih.gov/assembly/GCF_ 000008285.1 ) from NCBI database.

\section{Declarations}

Ethics approval and consent to participate

Not applicable.

\section{Consent for publication}

Not applicable.

\section{Competing interests}

The authors declare that they have no competing interests.

\section{Author details}

${ }^{1}$ Institute of Biotechnology, University of Helsinki, Helsinki, Finland. ${ }^{2}$ Faculty of Food Science and Engineering, Dunarea de Jos University of Galati, Galati, Romania. ${ }^{3}$ Department of Chemical Engineering, Norwegian University of Science and Technology (NTNU), Trondheim, Norway. ${ }^{4}$ Department of Process Technology, Nofima-Norwegian Institute of Food, Fisheries and Aquaculture Research, 4068 Stavanger, Norway. ${ }^{5}$ Institute of Microbiology and Biotechnology, Ulm, University, Albert-Einstein-Allee 11, 89081 Ulm, Germany. ${ }^{6}$ Present Address: Blueprint Genetics, Espoo, Finland.

Received: 16 February 2021 Accepted: 2 April 2021

Published online: 15 April 2021

\section{References}

1. EFSA Panel on Biological Hazards BIOHAZ, Ricci A, Allende A, Bolton D, Chemaly M, Davies R, et al. Listeria monocytogenes contamination of ready-to-eat foods and the risk for human health in the EU. EFSA J. 2018;16:e05134.

2. Bucur Fl, Grigore-Gurgu L, Crauwels P, Riedel CU, Nicolau Al. Resistance of Listeria monocytogenes to stress conditions encountered in food and food processing environments. Front Microbiol. 2018. https://doi.org/10.3389/ fmicb.2018.02700.

3. Gahan CGM, Hill C. Listeria monocytogenes: survival and adaptation in the gastrointestinal tract. Front Cell Infect Microbiol. 2014. https://doi.org/10. 3389/fcimb.2014.00009.

4. NicAogáin $\mathrm{K}, \mathrm{O}$ 'Byrne CP. The role of stress and stress adaptations in determining the fate of the bacterial pathogen Listeria monocytogenes in the food chain. Front Microbiol. 2016. https://doi.org/10.3389/fmicb.2016. 01865.

5. Buchanan RL, Gorris LGM, Hayman MM, Jackson TC, Whiting RC. A review of Listeria monocytogenes: an update on outbreaks, virulence, doseresponse, ecology, and risk assessments. Food Control. 2017;75:1-13.

6. Chan YC, Wiedmann M. Physiology and genetics of Listeria monocytogenes survival and growth at cold temperatures. Crit Rev Food Sci Nutr. 2009:49:237-53.

7. Duru IC, Andreevskaya M, Laine P, Rode TM, Ylinen A, Løvdal T, et al. Genomic characterization of the most barotolerant Listeria monocytogenes RO15 strain compared to reference strains used to evaluate food high pressure processing. BMC Genomics. 2020;21:455. 
8. Duru IC, Bucur Fl, Andreevskaya M, Nikparvar B, Ylinen A, Grigore-Gurgu L, et al. High-pressure processing-induced transcriptome response during recovery of Listeria monocytogenes. BMC Genomics. 2021;22:117.

9. Bowman JP, Bittencourt CR, Ross T. Differential gene expression of Listeria monocytogenes during high hydrostatic pressure processing. Microbiology. 2008;154(Pt 2):462-75.

10. Martin M. Cutadapt removes adapter sequences from high-throughput sequencing reads. EMBnet J. 2011;17:10-2.

11. Bankevich A, Nurk S, Antipov D, Gurevich AA, Dvorkin M, Kulikov AS, et al. SPAdes: a new genome assembly algorithm and its applications to single-cell sequencing. J Comput Biol. 2012;19:455-77.

12. Seemann T. Prokka: rapid prokaryotic genome annotation. Bioinformatics. 2014;30:2068-9.

13. Törönen P, Medlar A, Holm L. PANNZER2: a rapid functional annotation web server. Nucleic Acids Res. 2018;46:W84-8.

14. Doumith $M$, Buchrieser C, Glaser P, Jacquet C, Martin P. Differentiation of the major Listeria monocytogenes serovars by multiplex PCR. J Clin Microbiol. 2004;42:3819-22.

15. Rice P, Longden I, Bleasby A. EMBOSS: the European Molecular Biology Open Software Suite. Trends Genet. 2000;16:276-7.

16. Moura A, Criscuolo A, Pouseele H, Maury MM, Leclercq A, Tarr C, et al. Whole genome-based population biology and epidemiological surveillance of Listeria monocytogenes. Nat Microbiol. 2016;2:1-10.
17. Darling AE, Mau B, Perna NT. progressiveMauve: multiple genome alignment with gene gain, loss and rearrangement. PLOS ONE. 2010:5:e11147.

18. Richter M, Rosselló-Móra R, Oliver Glöckner F, Peplies J. JSpeciesWS: a web server for prokaryotic species circumscription based on pairwise genome comparison. Bioinformatics. 2016;32:929-31.

19. Page AJ, Cummins CA, Hunt M, Wong VK, Reuter S, Holden MTG, et al. Roary: rapid large-scale prokaryote pan genome analysis. Bioinformatics. 2015;31:3691-3.

20. Price MN, Dehal PS, Arkin AP. FastTree 2-approximately maximum-likelihood trees for large alignments. PLoS ONE. 2010;5:e9490.

21. Untergasser A, Nijveen $H$, Rao X, Bisseling T, Geurts R, Leunissen JA. Primer3Plus, an enhanced web interface to primer3. Nucleic Acids Res. 2007;35(web server issue):W71-74.

22. Andreevskaya $M$, Jääskeläinen $E$, Johansson $P$, Ylinen $A$, Paulin $L$, Björkroth J, et al. Food spoilage-associated leuconostoc, lactococcus, and lactobacillus species display different survival strategies in response to competition. Appl Environ Microbiol. 2018. https://doi.org/10.1128/AEM. 00554-18.

\section{Publisher's Note}

Springer Nature remains neutral with regard to jurisdictional claims in published maps and institutional affiliations.
Ready to submit your research? Choose BMC and benefit from:

- fast, convenient online submission

- thorough peer review by experienced researchers in your field

- rapid publication on acceptance

- support for research data, including large and complex data types

- gold Open Access which fosters wider collaboration and increased citations

- maximum visibility for your research: over $100 \mathrm{M}$ website views per year

At BMC, research is always in progress.

Learn more biomedcentral.com/submissions 